\title{
A BRINQUEDOTECA E O BRINCAR NO HOSPITAL: DIÁLOGO ENTRE O LÚDICO E O TERAPÊUTICO
}

\author{
WIEZZEL, Andreia Cristiane Silva ${ }^{28}$ \\ VILLELA, Fábio Camargo Bandeira ${ }^{29}$
}

Recebido em: 2008-07-31

Aprovado em: $2008-08-28$

ISSUE DOI: $10.3738 / 1982.2278 .129$

RESUMO: O presente artigo resulta de projeto desenvolvido junto à crianças hospitalizadas, por equipe constituída por docentes e discentes da FCT/UNESP - Campus de Presidente Prudente. Tem como objetivo analisar a possibilidade de minimização da angústia e do sofrimento decorrentes deste processo às mesmas por meio de atividades lúdicas e relacionais. O referido trabalho perpassa análise de políticas públicas para a infância, estudo de autores de linha psicanalítica, tais como Donald W. Winnicott e Melanie Klein e também observações e intervenções, com o apoio do método psicanalítico, em ala de pediatria. $\mathrm{O}$ estudo demonstra que o brincar no hospital favorece o processo de humanização e minimiza o sofrimento da criança e de seus familiares - decorrente da doença e da hospitalização - , contribuindo no processo de cura.

Palavras-chave: Crianças hospitalizadas. Vida emocional. Brinquedoteca.

SUMMARY: The present article results from a project developed for hospitalized children by a group of teachers and students from FCT/UNESP Campus of Presidente Prudente. It has as objective investigates the possibility to decrease the usual level of anguish and current suffering of these children through playing and connected activities. This work is related to public policy and to psychoanalytical theories, especially from Donald W. Winnicott and Melanie Klein. Observations and interactions with the support on the psychoanalytical method are also considered. The study demonstrates that playing in the hospital helps the humanization process and minimizes child's and family's pain from the disease and the hospitalization, thereby helping with the cure process.

Keywords: Hospitalized children. Emotional life. Toy library.

\footnotetext{
${ }^{28}$ Professora de Psicologia da Aprendizagem e do Desenvolvimento do Departamento de Educação da FCT/UNESP Campus de Presidente Prudente. andreia@ fct.unesp.br

${ }^{29}$ Professor de Psicologia da Aprendizagem e do Desenvolvimento do Departamento de Educação da FCT/UNESP Campus de Presidente Prudente. fabiocbv@ stetnet.com.br
} 


\section{INTRODUÇÃO}

A humanização hospitalar, que se traduz como atendimento humanizado aos pacientes e seus acompanhantes, tem sido objeto de preocupação desde a primeira metade do século passado. Entretanto, em nosso país, apenas ganhou a devida atenção e importância, constituindo-se em política nacional de saúde, na última década.

As Brinquedotecas Hospitalares surgem como uma das iniciativas para promover a humanização no hospital, através do atendimento diferenciado à criança em consulta ambulatorial ou em internação em decorrência de acidente ou doença, e ganha status de obrigatoriedade junto ao setor de pediatria hospitalar a partir do ano de 2005, por meio da Lei Federal n ${ }^{\circ} 11.104 / 2005$.

Sua recente expansão, bem como sua recente adoção sistemática por parte dos hospitais, coloca em foco não apenas sua obrigatoriedade, mas sua própria delimitação teórica e programática no interior dos hospitais.

O Departamento de Educação da Faculdade de Ciências e Tecnologia da UNESP Campus de Presidente Prudente - desenvolve com participação de alunos de diferentes cursos de graduação o projeto de Brinquedoteca Hospitalar junto ao Hospital Estadual Dr. Odilo Antunes de Siqueira de Presidente Prudente desde 1999, atendendo à demanda do hospital através de aproximadamente 50 atendimentos mensais.

A área de atuação, bem como a linha do projeto, são interdisciplinares, envolvendo as áreas de saúde e educação. Conta, atualmente, com a participação de dois professores de Psicologia do Departamento de Educação, 50 alunos da graduação, envolvendo os cursos de Pedagogia, Educação Física e Fisioterapia, bem como de profissionais voluntários, pedagogas e fonoaudióloga.

Ultrapassadas as dificuldades de criação e manutenção da brinquedoteca, o projeto atualmente está em fase final de consolidação de uma sistemática de trabalho que envolve atendimentos a crianças e seus acompanhantes não apenas no espaço destinado a brinquedoteca mas, sobretudo, nos leitos. Há a possibilidade, para os próximos anos, de estender os atendimentos a gestantes de alto risco e prematuros.

A partir de 2007, considerando a avaliação positiva do trabalho realizado pela equipe do hospital, bem como demonstrações de satisfação por parte das crianças e seus acompanhantes, pensou-se, na mesma perspectiva delineada por Magalhães (2002), na possibilidade de explorar a brinquedoteca como espaço privilegiado para uma investigação 
mais sistemática sobre o brinquedo, o brincar e seus efeitos sobre crianças hospitalizadas. Assim, estava criado o embrião do projeto que será apresentado a seguir.

\section{A CRIANÇA E A HOSPITALIZAÇÃO}

A instituição hospitalar preocupa-se com a reabilitação do ser humano, com a continuidade do desenvolvimento saudável. Para que possa realizar seu objetivo de propiciar a saúde, é fundamental que cuide dos indivíduos levando em consideração seus aspectos físicos e psíquicos, reconhecendo a importância do inter-relacionamento entre tais aspectos. No que se refere ao cuidado destinado ao psíquico, é importante que o atendimento hospitalar crie condições para que os indivíduos possam se expressar espontaneamente e ter contato com atividades que se contraponham à sua estrita submissão aos procedimentos técnicos.

Quando o atendimento é destinado a bebês e crianças, a atenção voltada ao aspecto emocional é ainda mais necessária, uma vez que a estruturação da psique ainda está em desenvolvimento e as pressões do ambiente podem incidir negativamente sobre esta. Como a criança está em desenvolvimento, ainda não tem condições, do ponto de vista de recursos psíquicos, para enfrentar a experiência de hospitalização. Dependendo de sua idade, se encontra, segundo Winnicott (1982), em estreita relação de dependência com a mãe, sendo que a privação em relação a esta pode causar uma descontinuidade em seu desenvolvimento, em grau bastante prejudicial a este. Spitz (1979) ressalta que a privação materna, tanto a parcial como a total, só tem a impactar negativamente no desenvolvimento infantil, podendo produzir carências, problemas nos relacionamentos sociais, alterações somáticas, distúrbios nervosos, dentre outros.

No hospital, a criança deixa de habitar um ambiente que é familiar. Durante a internação, fica afastada das atividades diárias, deixa de ir à escola, conviver com amigos, pais, irmãos e outros familiares. Apesar de lhe ser explicado que o hospital é um local onde se realizam tratamentos para evitar a dor e curar doenças (portanto, algo bom), ela também fica submetida a intrusões a seu corpo, que acontecem através de procedimentos e instrumentos terapêuticos que assustam e causam dor (e, por isso, são sentidos como algo ruim), dos quais a criança sente a necessidade de se proteger. Nesse cenário, reconhecer e se relacionar de forma tranqüila com os aspectos bons e ruins do hospital se torna uma tarefa difícil.

Conforme Luz; Villela (2007), no hospital, as crianças sentem medo, têm choro 
incontido, podem perder o apetite, ficar desesperadas ou demasiadamente submissas diante dos procedimentos hospitalares e da presença da equipe técnica do hospital. Além disso, algumas delas apresentam sintomas como dor, febre, vômito, para os quais não se encontram explicações através da realização de exames, que indicam a integridade do aspecto físico. Tais dificuldades revelam-se como efeito do sofrimento psíquico, seja pelo fato da privação materna, seja pelas intrusões ou fantasias criadas pelas crianças a respeito dos motivos que a levaram a estar no hospital.

\section{O BRINCAR NO HOSPITAL}

O brincar e suas diferentes dimensões ligadas ao lúdico e ao ato educativo têm sido investigado por diversos autores. Na linha do projeto em questão, o brincar é estudado do ponto de vista da psicanálise, já que os objetivos do trabalho perpassam a humanização, a privação e os aspectos emocionais presentes em tais processos em situação específica de hospitalização.

Dentre os autores em psicanálise, o referencial teórico privilegiado refere-se às formulações de Melanie Klein (1996), Winnicott (1982, 1990 e 2000) e Spitz (1979), que discutem, respectivamente, o método psicanalítico com crianças, o desenvolvimento emocional da criança e a relação maternal e os efeitos da hospitalização e do hospitalismo sobre a vida emocional e o desenvolvimento de crianças. Em Aberastury (1992) é desenvolvido um rápido mapeamento das atividades lúdicas infantis como expressão plástica do desenvolvimento e da vida da fantasia na criança.

Conforme o referencial teórico psicanalítico, ao brincar livremente, a criança, ao mesmo tempo em que sente prazer, comunica seus sentimentos. Essa comunicação torna possível o conhecimento dos possíveis conteúdos psíquicos que possam causar sofrimento, provocando inibições e angústias. Aberastury (1992) aponta a relação estabelecida entre o brincar e a expressão de conflitos:

Por meio da atividade lúdica, a criança expressa seus conflitos e, deste modo, podemos reconstruir seu passado, assim como no adulto fazemo-lo através de palavras. Esta é uma prova convincente de que o brinquedo é uma forma de expressar os conflitos passados e presentes (p.17). 
Distante das atividades cotidianas, brincar no hospital aparece como uma possibilidade de promover o bem-estar psíquico da criança. Ao brincar, a criança pode ser espontânea, pode usar sua criatividade livremente. Através dos brinquedos, repete ou inventa situações cotidianas que vivenciou, tranqüilizando-se, obtendo prazer e elaborando situações traumáticas:

O brinquedo possui muitas das características dos objetos reais, mas, pelo seu tamanho, pelo fato de que a criança exerce domínio sobre ele, pois o adulto outorgalhe a qualidade de algo próprio e permitido, transforma-se no instrumento para o domínio de situações penosas, difíceis, traumáticas, que se engendram na relação com os objetos reais. Além disso, o brinquedo é substituível e permite que a criança repita, à vontade, situações prazenteiras e dolorosas que, entretanto, ela por si mesma não pode reproduzir no mundo real (p. 15).

Winnicott (1982) aponta, ainda na perspectiva do brincar, a questão específica da angústia:

\footnotetext{
Conquanto seja fácil perceber que as crianças brincam por prazer, é muito mais difícil para as pessoas verem que as crianças brincam para dominar angústias, controlar idéias ou impulsos que conduzem à angústia se não forem dominados. A angústia é sempre um fator na brincadeira infantil e, freqüentemente, um fator dominante (p. 162)
}

As brincadeiras aparecem, na expressão infantil “[...] como um elo entre, por um lado, a relação do indivíduo com a realidade interior e, por outro lado, a relação do indivíduo com a realidade externa ou compartilhada" (WINNICOTT, 1982, p.164) Diante destas considerações, fica patente a legitimidade em se pesquisar os efeitos da brincadeira em situação hospitalar.

O brincar e a brinquedoteca em hospitais constitui assunto ainda pouco explorado, embora haja experiências ocorrendo em tais locais. Quando se fala em brinquedoteca, o mais comum é que os estudos apontem a existência das mesmas em escolas ou então ligadas a centros comunitários e bibliotecas. (ANDRADE; ALTMAN, 1998)

Ressalta Magalhães (2002) que apesar de as brinquedotecas hospitalares e escolares serem próximas quanto às características físicas entre si, seus objetivos e funções são diferenciados. A criação de brinquedotecas permite tal diversidade, à medida que visa atender 
demandas particulares. Nessa perspectiva, acredita-se que estudos específicos a cada contexto serão muito benéficos ao desenvolvimento e implementação das brinquedotecas hospitalares.

Brincar no hospital é sinônimo de pesquisa sobre quem é a criança, seu desenvolvimento, suas necessidades, como o relacionamento com os progenitores afeta o seu desenvolvimento e como o brincar pode contribuir na expressão e elaboração de conflitos, como a internação pode afetar a vida psíquica da mesma e, finalmente, como garantir à criança que as brinquedotecas e as atividades decorrentes, sejam um espaço onde possa se expressar e ser acolhida. Este é o teor dos estudos teóricos que vêm ocorrendo entre a equipe responsável pelo projeto.

\section{O PROJETO DE INTERVENÇÃO LÚDICA DESENVOLVIDO NO HOSPITAL}

O projeto desenvolvido no Hospital Estadual Dr. Odilo Antunes de Siqueira de Presidente Prudente tem por objetivo fundamental investigar se o sofrimento causado pela doença e pela abrupta separação do convívio social (família, amigos, escola, objetos pessoais, animais de estimação) pode ser minimizado por meio de expressão de sentimentos como medo, angústia, saudade, tensão e outros, através de atividades lúdicas e relacionais.

O Hospital Estadual atende a população da cidade e da região de Presidente PrudenteSP. A população atendida é carente e os atendimentos são realizados via Sistema Único de Saúde. O Hospital dispõe de pediatria, maternidade, berçário, centro cirúrgico e Unidade de Terapia Intensiva (inclusive neonatal).

Há o desenvolvimento de vários projetos nesse espaço, alguns deles vinculados aos objetivos de humanização. No caso da Brinquedoteca, o projeto resultou de parceria entre o hospital e o curso de Pedagogia da Faculdade de Ciências e Tecnologia - UNESP/Presidente Prudente.

Entre os meses de janeiro a dezembro de 2007, 367 crianças entre 2 e 7 anos, que estiveram hospitalizadas no Hospital Estadual Dr. Odilo Antunes de Siqueira de Presidente Prudente - SP e, de forma indireta, alguns pais foram sujeitos da presente pesquisa.

Os alunos foram preparados com relação à fundamentação teórica e intervenção por meio de participação em grupos de estudos e cursos de extensão, contando, no decorrer do trabalho com a supervisão dos professores de Psicologia coordenadores do projeto e de uma pedagoga. 
Os encontros, no hospital, duraram cerca de 1 hora e foram diários, incluindo os sábados. O material utilizado envolveu brinquedos de vários tipos, material para pintura, livros de estórias. O projeto foi submetido ao Comitê de Ética da FCT-UNESP/Presidente Prudente.

As intervenções ocorreram tanto no espaço da brinquedoteca quanto nos leitos. O atendimento era realizado nos leitos quando se verificava que a criança não poderia sair daquele espaço. Os pesquisadores dispunham de caixas onde transportavam alguns brinquedos, selecionados com atenção às teorias de Klein e Aberastury e convidavam as crianças para brincar.

A coleta de dados foi realizada por 50 alunos, oriundos dos cursos de graduação em Pedagogia e Fisioterapia, e ocorreu por meio de estabelecimento de vínculo e interação através de atividade lúdica. Após o encontro, o estagiário refletia sobre a interação e interpretava as reações da criança e o tipo do vínculo estabelecido, bem como suas próprias reações frente a esta e realizava registros sistemáticos dessas experiências. Cada momento foi minuciosamente registrado num aplicativo web desenvolvido especialmente para gerenciar o projeto. Os registros dos alunos eram analisados pelos professores dos grupos de estudos que marcava posterior surpervisão para orientação e explicitação de aspectos da interação não percebidos pelos mesmos.

O material de análise durante e após os encontros transcendeu a verbalização das crianças, envolvendo também seu relacionamento com os brinquedos, suas escolhas, seus gestos, suas expressões.

\section{RESULTADOS}

Durante o ano de 2007 foram registradas 457 visitas com vistas à pesquisa, bem como contatos com 190 pais e 367 crianças. A disparidade entre o número de visitas e o de crianças, refere-se ao fato de que uma mesma criança foi atendida mais de uma vez, e pelo fato de estarem internadas e as visitas serem semanais. Dessas 367 crianças, a que contou com maior número de atendimentos obteve 17 visitas, e 31crianças tiveram apenas uma visita, em decorrência de sua curta estada no hospital.

Em análise dos dados registrados, pode-se obter o seguinte, em linhas gerais, com 
relação ao objetivo central do trabalho: pode-se observar uma mudança no estado emocional das crianças antes e depois das intervenções. Conforme os registros, antes do início da brincadeira, as crianças geralmente se encontravam tristes, quietas, desanimadas. No decorrer da brincadeira, aos poucos, o envolvimento, bem como o sorriso, a alegria e as conversas, surgiam. As crianças pareciam esquecer que estavam internadas e doentes. Além disso, demonstravam entusiasmo e relativa tranqüilidade ao final das atividades, como ressaltaram duas das alunas participantes do projeto:

E depois de terminar esse momento mágico percebia-se no rosto e nos gestos da criança uma incrível sensação de alivio e alegria; algumas até pediam para ficarmos mais um pouco. Aquela brincadeira era um momento único de sentir e reviver suas experiências emocionais e do dia a dia, que foram interrompidas pelo processo de internação.

Com o trabalho pude comprovar que a brincadeira no hospital tem uma eficácia na rotina hospitalar da criança, é como se injetássemos uma boa dose de alegria nas crianças e nos pais, que também se interessavam e até criavam um vínculo maior com o seu filho (a).

O brincar ofereceu, ainda, a possibilidade de externalização de medos, angústias, favorecendo maior estabilização emocional infantil e ampliação da capacidade da criança para elaborar conflitos decorrentes da situação de internação, o que colabora na amenização do sofrimento e angústia.

Paralelamente, foram registrados dados que apontam para outros resultados positivos, para além dos já mencionados e investigados: mudanças teóricas e de conduta da equipe técnica a respeito do lúdico e de sua necessidade na vida da criança, criando-se condições para que se promova a humanização hospitalar; estreitamento das relações entre mães e filhos, especialmente no contexto hospitalar e favoreceu o desenvolvimento das habilidades lúdicas nas mães, estimulando, também, o brincar entre as últimas e suas crianças.

Ainda pôde ser observada uma melhora nos relacionamentos, conforme um dos alunos relatou:

Com o trabalho, houve maior integração entre crianças internadas e o meio hospitalar, 
maior estabilização emocional das crianças, estreitamento das relações entre mães e filhos e trocas de informações entre participantes do projeto e equipe técnica, modificando-se a concepção sobre a importância do lúdico na vida e no tratamento das crianças em seu período de internação e no contexto hospitalar em sentido mais amplo.

Além disso, apareceu também o resgate do direito de brincar, aliado ao processo de humanização:

Os acompanhamentos de casos nos mostram que a criança recupera o seu direito de brincar, pois, na internação, ela se encontra fragilizada tanto pelo sofrimento físico, quanto pela abrupta separação do seu convívio social. A rotina hospitalar é alterada com o ingresso do lúdico, contribuindo efetivamente no processo de maior humanização do tratamento pediátrico e beneficiando as crianças em seu bem estar e melhor perspectiva de evolução do tratamento em muitos casos.

Algo também mencionado, e digno de nota, é o fato de a criança aprender a lidar com situações novas e com os conflitos advindos destas:

Através da brincadeira, ajuda-se a criança internada a amenizar a dor, a angústia, a saudade de casa ou dos amigos, ou seja, a lidar com o novo e com os conflitos gerados por conta da doença e da internação.

Os dados mostraram, também, algumas situações que demandam atenção:

Um caso que me chamou muito a atenção foi o da pequena "Maria", de 3 anos de idade, que estava internada devido a uma forte estomatite. Ela teve alta e acabou voltando um dia depois com uma bronquite asmática (doença psicossomática). Nesta visita, o que mais me chamou a atenção foi quando uma estagiária de medicina entrou em seu quarto. Ao vê-la, Maria ficou eufórica demonstrando conhecê-la e logo “ de cara” a cumprimentou, dizendo “oi”. Porém, a estagiária, acompanhada pelo médico responsável, não lhe deu atenção e nem sequer respondeu ao seu “oi”. Estes, ao examiná-la, logo saíram. Maria mostrou-se muito decepcionada ao perceber que a estagiária nem olhou para 
ela.

Tal fato demonstra a ocorrência de vínculos entre as crianças e a equipe. A partir do momento que a criança se envolve mais profundamente com alguém, sente conforto, sente que não está sozinha e a afetividade que se estabelece nestas trocas, traz segurança à criança. Em uma das visitas ocorridas no hospital, uma criança que já havia recebido alta alguns dias anteriores, veio ao encontro de uma das alunas participantes do projeto e disse: "Voltei!" Parecia contente em reencontrar uma pessoa "conhecida" naquele espaço. Além disso, quando as crianças encerram o tratamento, é comum que se despeçam dos alunos prometendo visitas e escrevam bilhetinhos carinhosos, como: "Você é linda!"; "Eu te amo". Tais atitudes demonstram o quanto é importante que a criança se sinta acolhida, valorizada e o quanto isto faz bem a ela.

Além da perspectiva da criança, foram observados resultados positivos também no tocante aos acompanhantes. Não raramente, quando as crianças recebiam visitas nos leitos, os familiares participavam das brincadeiras e estimulavam as crianças a se envolver também, encorajando-as. Outros pais preferiam dar uma volta pelo corredor, sair para descansar um pouco, enquanto os filhos brincavam.

As experiências demonstraram que tais vivências colaboraram para uma melhor adaptação dos acompanhantes à situação, bem como minimizou o desgaste e o sofrimento dos mesmos, pelo menos naqueles momentos específicos. Alguns pais se surpreenderam ao ver a capacidade do filho em brincar numa situação de doença.

Isto é muito relevante enquanto resultado, pois se sabe que os pais ou responsáveis pela criança também sentem desconforto com a situação: medo, insegurança, culpa, receio, dentre outros. Quanto mais puderem estar tranqüilos, mais adequadamente poderão auxiliar no apoio à criança, já que a forma como a última reage à hospitalização está ligada àquilo que vem de fora.

A criança, nestas condições, apresenta-se muito fragilizada, dando vazão à criação de fantasias, como citado anteriormente, a respeito dos motivos que a levaram a estar ali, podendo gerar ansiedade, culpa, medo do abandono. Se os pais ou responsáveis puderem apresentar-se de forma que a criança se sinta segura, ficará menos propensa a estes sintomas. Conforme pode ser observado, as brincadeiras constituem momento privilegiado para o estreitamento de tal vínculo hospitalar, pois auxilia na superação de inseguranças e medos verificados em ambos, resgatando seu vínculo afetivo como forma de contribuição na 
superação da doença.

\section{CONSIDERAÇÕES FINAIS}

O projeto de extensão e pesquisa desenvolvido é de extrema relevância social, tanto pelo reconhecimento legal da necessidade das brinquedotecas hospitalares na política nacional de humanização hospitalar, como pelo trabalho efetivo e amplo que se tem feito junto ao hospital.

A população atendida é extremamente carente e necessitada, dependendo, portanto, dos bons serviços que o setor público, incluindo a universidade e seus projetos de extensão e pesquisa, possa oferecer.

A relação com o hospital tem se mostrado bastante orgânica, e o projeto tem espaço para dar o conforto e auxiliar na elaboração de angústia das crianças e de seus acompanhantes, bem como para implementar novos projetos, inclusive em colaboração com setores do hospital.

As crianças, pais e acompanhantes se interessam pelas atividades desenvolvidas e costumam solicitar a presença dos alunos para realizar brincadeiras e fornecer conforto. Como forma de ampliação do trabalho, foi criado o programa de atendimento a bebês abandonados e/ou com síndrome de hospitalismo. Ainda que, em estado inicial, foi bastante promissor e a direção do hospital já sinalizou favoravelmente à existência de novos programas, entre os quais estão sendo pensados trabalhos com gestantes (especialmente de alto risco) e prematuros.

Os programas adotados, bem como o programa de atendimento a bebês com síndrome de hospitalismo, cujas atividades envolveu o oferecimento de um curso para tratar do tema, contou com a participação de vários profissionais do hospital de diferentes categorias. O projeto cria conhecimentos compartilhados e sinergias muito positivas entre universidade e hospital no atendimento das crianças, mães e gestantes.

O trabalho proporcionou o estabelecimento de vínculos e de relações lúdicas que promoveram na criança o desenvolvimento emocional e o desenvolvimento cognitivo dele decorrente, a humanização hospitalar, assim como debate sobre as feições desejáveis de uma brinquedoteca hospitalar.

Cooperou, indiretamente, com a própria equipe técnica do hospital, na medida em 
que as crianças tendiam a ficar mais tranqüilas, o que facilitava o tratamento e intervenções médicas. Favoreceu, ainda, a melhora da condição emocional das mães, bem como de sua capacidade para o estabelecimento de vínculos e atividades lúdicas com o filho internado.

A rotina hospitalar é alterada com o ingresso do lúdico, contribuindo efetivamente no processo de maior humanização do tratamento pediátrico e beneficiando as crianças em seu bem estar e melhor perspectiva de evolução do tratamento em muitos casos. Além disso, auxilia na continuidade do desenvolvimento emocional e, conseqüentemente, cognitivo da criança, ao passo que restabelece as situações de vínculos afetivos, seja entre a equipe e as crianças, seja entre o grupo das próprias crianças, seja com os pais e/ou acompanhantes, fortalecendo as condições emocionais de todos os envolvidos.

\section{REFERÊNCIAS}

ABERASTURY, A. A Criança e seus jogos. 2 ed., Porto Alegre, Artmed, 1992.

ANDRADE, C. M. R. J.; ALTMAN, R.Z. As brinquedotecas brasileiras. In: FRIEDMANN, A. et al. O direito de brincar: a brinquedoteca. São Paulo, Scritta, 1998. p. 239-251.

KLEIN, M. Personificação no brincar das crianças. In: KLEIN, M. Melanie Klein: amor, culpa, reparação e outros trabalhos. Rio de Janeiro, Imago, 1996. p.228-239.

LUZ, Tagiane M. R.; VILLELA, Fábio C. B. Pensando sobre o brincar winnicottiano em uma brinquedoteca hospitalar. In: CIPSI - COLETIVIDADE E SUBJETIVIDADE NA SOCIEDADE CONTEMPORÂNEA, 3, 2007, Maringá. CONGRESSO INTERNACIONAL, 3. SEMANA DE PSICOLOGIA: COLETIVIDADE E SUBJETIVIDADE NA SOCIEDADE CONTEMPORÂNEA, 9. Anais... Maringá: xpaeventos, 2007. p. 1-13.

MAGALHÃES, C. M. C. Criação e manutenção de brinquedotecas: reflexões acerca do desenvolvimento de parcerias. Psicologia: reflexão e crítica. v. 15, n. 1, Porto Alegre, 2002.

SPITZ, R. A. O primeiro ano de vida: um estudo psicanalítico do desenvolvimento normal e anômalo das relações objetais. São Paulo: Martins Fontes, 1979.

VILLELA, F. C. B. Brinquedoteca hospitalar: diálogo entre o lúdico, o terapêutico, o ensino e a pesquisa. Relatório parcial - PROEX- FCT-UNESP/Presidente Prudente. (texto não publicado)

WINNICOTT, D.W. A Criança e seu mundo. 6 ed., Rio de Janeiro: LTC, 1982.

WINNICOTT, D.W. Natureza humana. Rio de Janeiro: Imago, 1990.

WINNICOTT, D.W. Da pediatria à psicanálise. Rio de Janeiro: Imago, 2000. 